\title{
Teacher Applicants' Self-Efficacy and English Proficiency
}

\author{
Vanesa B. Dungog a, Joefel T. Libo-on ${ }^{a, b, *}$
}

a Faculty of College of Arts and Sciences, Romblon State University, Odiongan, Romblon, Philippines.

b Faculty of Graduate Education and Professional Studies, Romblon State University, Odiongan, Romblon, Philippines.

*Corresponding author Ph: +639776231440; Email: onemanbrave@gmail.com

DOI: https://doi.org/10.34256/ajir2133

Received: 18-06-2021; Revised: 05-07-2021; Accepted: 07-07-2021 Published: 16-07-2021

Abstract: Self-efficacy is a belief in one capability in accomplishing a particular task. Most of the related studies concluded that having a high self-efficacy has something to do with high performance at work. It has something to do with an individuals' work output/ production; however, some other literature revealed that it does not have something to do with an individual's performance. On the other side, the English language is the required medium of instruction yet the most feared. This study investigated the self-efficacy towards the English Proficiency Test of the teacher applicants from the Division of Romblon. Findings showed that respondents have Low Self- efficacy status towards English Proficiency Test. It concluded that proficient respondents have a Very Low Self-efficacy among the levels of English Proficiency compared to other levels that reached the Low level. Further, the overall English Proficiency of teacher applicants was at the Beginners level.

Keywords: English, Proficiency, Self-efficacy, Philippines.

\section{Introduction}

Self-efficacy certifies an individual's proficiency, for it embodies competence and performance in the workplace (Artino, Jr., 2012). It also presents how an individual exerts efforts in a specific work (Wyatt, 2020). Studying teachers' credibility in terms of the English language is vital to view how they devote themselves to the importance of education. Self-efficacy is one way of evaluating teachers' teaching practice (Khanshan \& Yousefi, 2020). The research of (McDonough 2019) revealed that school administrators and principals must develop and retain highly qualified teachers who are early in their careers, based upon the concept of self-efficacy and data showing a lack of perceived competency in key teaching components. Academe must assure stakeholders that aligning to globalization is being achieved, like communication skills in English.

Throughout the year, English language proficiency contributes a significant portion to developing the country's socio-economic system. In the Philippines, English is the essential means of message in business and instruction; henceforth, acquiring the language has become a pre-imperative to accomplishment in scholarly and business environments (Digap, 2016). On the contrary, English is perceived to be the most feared language, according to (Jugo 2020). Education needs a skilled workforce in English literacy, which is presently the primary medium of instruction in the academe to ensure quality education and economic advancement. The English Proficiency Test as the national examination included in the hiring process of teacher applicants could examine the interventions suited for developing the teachers' credibility in work. Numerous studies exposed that the excellence of education in the Philippines is unceasingly decreasing (Racca \& Lasaten, 2016) to the point that the Professional Regulatory Commission (PRC) testified that the passers of board examination in all fields of specialization continue to lower. One of the crucial causes for this challenge is the academic failure of the primary education system.

Unfortunately, Filipino workers' competence in English is declining, and the disturbing part is that untrained and non-proficient teachers are heavily blamed (Meniado, 2018). In support of this declaration, the Department of Education led a study in 2008 discovering that 80 percent of secondary school teachers in the Philippines failed an English Proficiency Test. These studies express teachers' low proficiency in English. Hence generating graduates with comparatively a similar proficiency level is too alarming. 


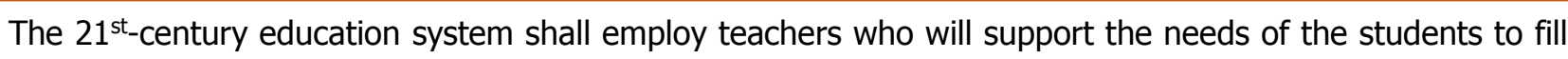
in the arising gaps since education is an avenue to the employability trend of young professionals (Egel, 2009). As to (DePiper et al. 2021), the educational institution must ensure the innovativeness and confidence of teachers in terms of teaching using the second language (L2), especially to other subjects like Science and Mathematics. The eloquence of the target language, especially the significance of the four linguistic skills; (i.e., listening, speaking, writing, and reading), is necessary for the learners to achieve complete learning. They will justify the quality of education that the country has been providing. The enhancement of every department under education must uplift the importance of strict implementation of the English language. In such a way, the school administrators guaranteed that their human resource competes globally and can alter the perception of neighboring countries about the current status of the English Proficiency Level of the Philippines.

This status of declination is asking for an adequate resolution/ intervention. Certainly, created interventions must meet the objectives and have a satisfying impact on the institution. High-performance consistency in using the foreign language is a prerequisite to certifying Filipino inclusion in the global arena. The English Proficiency Test result of the teachers must be coherent with their teaching performance inside the $21^{\text {st }}$ century classrooms. As for the researchers' observation, some of the K12 graduates who pursued college were having a hard time using and comprehending English. In this matter, it must check if the delivery of the language essentials is consistent and if the students' exposure to the English language is sufficient. The education's commitment to reinforce the need and demand must be elevated for us not to be left behind. It is a call to all educators to pre-define the present issue before it turns into an unresolvable matter. The researchers conducted this study for the needs and sustainability of the education system based on the given findings and conclusion stipulated in other studies and literature.

This study targeted to (a) determine the self-efficacy status of the teacher applicants in the Department of Education (Division of Romblon) towards English Proficiency Test; (b) determine the English Proficiency Level of the teachers in terms of the following Linguistic skills: Structure, Written Expression, and Reading Comprehension; (c) determine if the reading and Writing self-efficacy are the same across any field of specialization; and (d) determine if there is a relationship between efficacy and proficiency.

Figure 1 presents the pattern of this research. Since this study opted to determine the Self-efficacy of teacher applicants toward the English Proficiency Test, there is a need to collect all the essential documents. Initially, the requested English Proficiency Test 2018 result from the Department of Education - Division of Romblon was analyzed to define its proficiency levels. Then, the dissemination of a self-made Self-Efficacy questionnaire happened through an online survey. Finally, the results of an online survey determined the respondents' Self- Efficacy towards the English Proficiency Test.

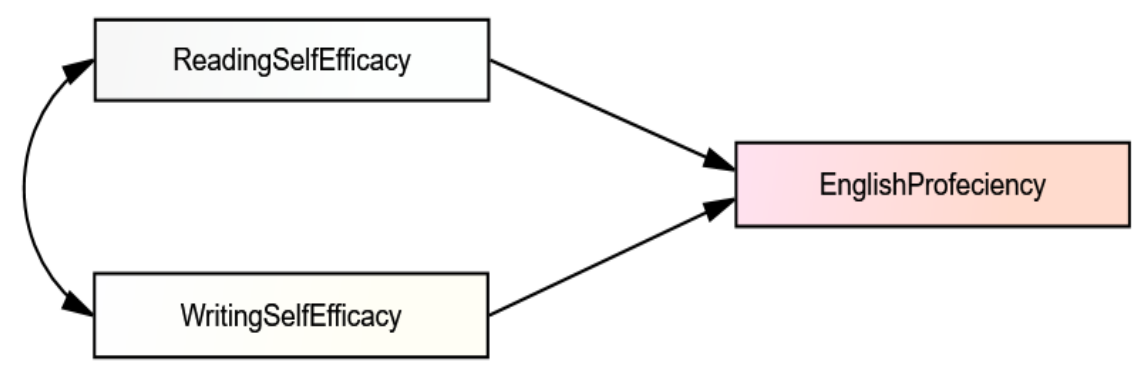

Figure 1. Schematic Diagram

\section{Methods}

\subsection{Research Design}

This study utilized a descriptive-correlational research method to characterize the English Proficiency Level and Self-Efficacy of teacher applicants. Correlational was used to check the relationship between the variables, as mentioned earlier (Beauvais et al., 2014). 


\subsection{Population and Sampling Techniques}

The respondents of this study were the teacher applicants of the Division Office of Romblon - Department of Education. They were randomly selected from 244 total applicants with 229 turnarounds or $93.85 \%$. The necessary permission and communication relevant to the study were done before gathering the data.

\subsection{Instrumentation}

Researchers collected the data in different manners. The data on self-efficacy were done through the researchers-made questionnaire disseminated using the virtual survey form. Also, the English Proficiency Test result was requested from the Division Office of the Department of Education. The researchers-made questionnaire was validated to assess its face and content validity. In the validation process, copies of the questionnaire and research queries were given to three (3) jurors as the validators whose expertise is in measurement and evaluation. The researchers also conducted a pilot testing on the graduating students of the College of Education for reliability testing. The reliability test of Cronbach's Alpha has resulted in 0.92 .

\subsection{Data Analysis}

The data processing used various statistical tools, e.g., weighted mean; composite mean; ANOVA OneFactor; Pearson's Moments Correlation. All the data gathered was analyzed, tallied, and tabulated using IBM SPSS v.25.

\section{Results and Findings}

The succeeding data are the product of this study; discussions were placed right after the presented tables.

Table 1. Self- efficacy in Reading towards English language Proficiency

\begin{tabular}{lll}
\hline \multicolumn{1}{c}{ Statements } & Mean & Rank \\
\hline 1. I have advanced reading skills in the English language. & 2.19 & 5.00 \\
2. I feel proud of myself every time I read English reading materials. & 1.90 & 11.00 \\
3. I am confident with the adeptness of my vocabulary, which helps me read. & 2.11 & 6.50 \\
4. I value employing comprehension in reading any English printed material. & 1.72 & 14.00 \\
5. I am willing to help someone poor at understanding English texts. & 1.71 & 15.00 \\
6. I deliver the correct accent and pronunciation during the English reading session. & 2.32 & 3.00 \\
7. I can easily detect errors in English grammar when reading. & 2.51 & 1.00 \\
8. I am sure of the reading strategy/is to be applied. & 2.36 & 2.00 \\
9. I know how to quickly get the main topic of any passage that I read. & 2.11 & 6.50 \\
10. I do an evaluation every after reading if the author's perspectives are the same as mine. & 2.28 & 4.00 \\
11. I am motivated to read English books, for it will elevate my knowledge of anything. & 1.73 & 13.00 \\
12. I force myself to read more books for an in-depth rationalization/ explanation of the topic & 2.06 & 8.00 \\
assigned to me. & 2.03 & 9.00 \\
13. I am reading a lot in English in requisite to strengthen my spelling skill. & 1.97 & 10.00 \\
14. I incline myself in reading English since it is the most widely used language of many & \\
academic books. & 1.80 & 12.00 \\
15. I believe that by reading English materials, I can think analytically and critically. $\quad \mathrm{CM}$ & 2.05 & $\mathrm{~L}$
\end{tabular}

Legend: 1.00-1.71 Very Low (VL); 1.72-2.53 Low (L); 2.54-3.35 Medium (M); 3.36-4.17 High (H); 4.18-5.00 Very High $(\mathrm{VH}) ; \mathrm{CM}=$ Cumulative Mean

The above tables (Table 1\&2) exposed that teacher applicants in the Division of Romblon have a low status of self-efficacy towards Writing and Reading the English language. Hitting low self-efficacy in both linguistic skills reflects that teacher applicants do not have the desired or expected self-efficacy before taking the said examination, impacting their examination result and teaching works. These statuses of self-efficacy towards the English Proficiency Test covering Reading and Writing agree with the study of (Feng et al. 2019), stating that teachers' self-efficacy is critical since it foresees future behavior and impact turnovers. Most of them start their 
career with moderate to high self-efficacy for teaching. However, they frequently undergo a sharp debility during the first year.

Furthermore, testing self-efficacy was essential in the field of teaching. Since this is also the status, it affirms that the Philippines needs more study like this. (Topkaya \& Yavuz 2011) discovered that studies on selfefficacy perceptions are incredibly scarce in English language teaching.

Table 2. Self- efficacy in Writing towards English language Proficiency

\begin{tabular}{lll}
\hline \multicolumn{1}{c}{ Statement } & Mean & Rank \\
\hline 1. I have advance writing skills in the English language. & 2.47 & 1.00 \\
2. I feel proud of myself once I finish writing using the English language. & 1.95 & 8.00 \\
3. I am confident with the words I use in writing because of my broad vocabulary. & 2.37 & 3.00 \\
4. I give importance to every Academic Writing, especially those in English written materials. & 2.02 & 7.00 \\
5. I am willing to help someone who has difficulty in writing the English language. & 1.93 & 9.50 \\
6. I see that my ideas are well presented based on the patterns of organization in writing. & 2.04 & 6.00 \\
7. I write sentences that are free from grammatical errors. & 2.38 & 2.00 \\
8. I reread my written output and make sure that the language of it is clear. & 1.72 & 15.00 \\
9. I am consistent with my punctuation usage. & 2.14 & 4.00 \\
10. I avoid plagiarism in all of my written outputs. & 1.87 & 11.00 \\
11. I am motivated to write using the English language for I want to explain myself certainly. & 2.07 & 5.00 \\
12. I motivate myself to write in English because it allows me to conceptualize my thoughts. & 1.93 & 9.50 \\
13. I am more likely to succeed if I can write well. & 1.81 & 13.50 \\
14. I think of the goal I wanted to achieve in my writing. & 1.86 & 12.00 \\
15. I ask myself to give effort in all of my English writings. & 1.81 & 13.50 \\
& $2 M$ & 2.03 \\
\hline
\end{tabular}

Legend: 1.00-1.71 Very Low (VL); 1.72-2.53 Low (L); 2.54-3.35 Medium (M); 3.36-4.17 High (H); 4.18-5.00

Very High $(\mathrm{VH}) ; \mathrm{CM}=$ Cumulative Mean

Table 3. Proficiency Level: Structure, Written Expression, and Reading Comprehension

\begin{tabular}{lccccccc}
\hline \multicolumn{1}{c}{ Linguistic Skills } & n & Minimum & Maximum & M & SD & DI & R \\
\hline Structure & 229 & 13 & 100 & 62.33 & 15.68 & $\mathrm{~B}$ & 2 \\
Written Expression & 229 & 16 & 84 & 49.90 & 15.05 & $\mathrm{~B}$ & 3 \\
Reading Comprehension & 229 & 38 & 90 & 72.17 & 8.73 & $\mathrm{~B}$ & 1 \\
\hline
\end{tabular}

Legend: Beginners (B) - $74 \%$ and below; Developing (D) - 75\%- 80\%; Approaching

Proficient (AP) - 81\% - 86\%; Proficient (P) - 87\%- 91; Advance (A) - 92\% - 100\%; R=Rank

The English Proficiency Test comprising three (3) sections of multiple-choice type of test, namely Structure, Written Expression, and Reading Comprehension (Table 3), evaluates the English proficiency of the respondents. It is being administered for three hundred (300) minutes. The three linguistic skills were tagged as 'Beginners,' accumulating low scores.

Table 4. Self-efficacy in English in terms of Field of Specialization

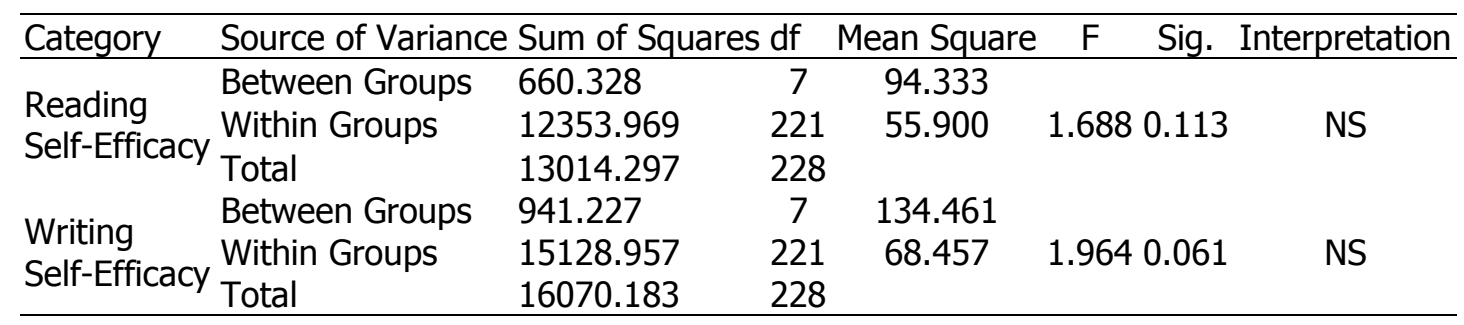

Table 5. Self-efficacy status and English Proficiency Test Result Correlation

\begin{tabular}{lcccc}
\hline Variables & $\mathrm{N}$ & $\mathrm{r}_{\mathrm{xy}}$-value & $\mathrm{p}$-value & Description \\
\hline Reading Efficacy $\rightarrow$ English Proficiency & 229 & -0.109 & 0.100 & Not Significant \\
Writing Efficacy $\rightarrow$ English Proficiency & 229 & $-0.143^{*}$ & 0.031 & Significant \\
\hline *. Correlation is significant at the 0.05 level (2-tailed). & &
\end{tabular}


The respondents' self-efficacy as to their field of specialization (Table 4) has no significant difference in the respondents' self-efficacy in reading, $F(7,221)=1.688, p=0.113$. In the same way, there has no significant difference in the respondents' self-efficacy in terms of writing, $F(7,221)=1.964, p=0.061$. It only indicates that the level of selfefficacy of the teachers is approximate at the same level.

Table 5 revealed the correlation between self-efficacy and English proficiency. The Reading efficacy and English Proficiency has no significant correlation, $\mathrm{r}_{\mathrm{xy}}(229)=-0.109, p=0.100$. It means that reading efficacy does not affect English Proficiency in any manner. The result contradicts the study made by (Tanyera 2015) in which, Self-efficacy in Reading (SER) was absolutely and significantly correlated to Reading performance.

On the contrary, writing efficacy and English proficiency have a significant correlation, $\mathrm{r}_{\mathrm{xy}}(229)=-0.143$, $p=0.031$. It means that writing efficacy is correlated to writing proficiency. It established a negative correlation that as the status of writing efficacy goes up, the English Proficiency status goes down, as shown in Figure 2. These results also coincide with the study of (Yilmaz 2011), which indicated that teachers' perceived efficacy correlates with their self-reported English proficiency. The study provides valuable insights into the need to help teachers develop their language proficiency that, in turn, has relevance for their perceived self-efficacy. Also, writing efficacy is correlated to English proficiency.

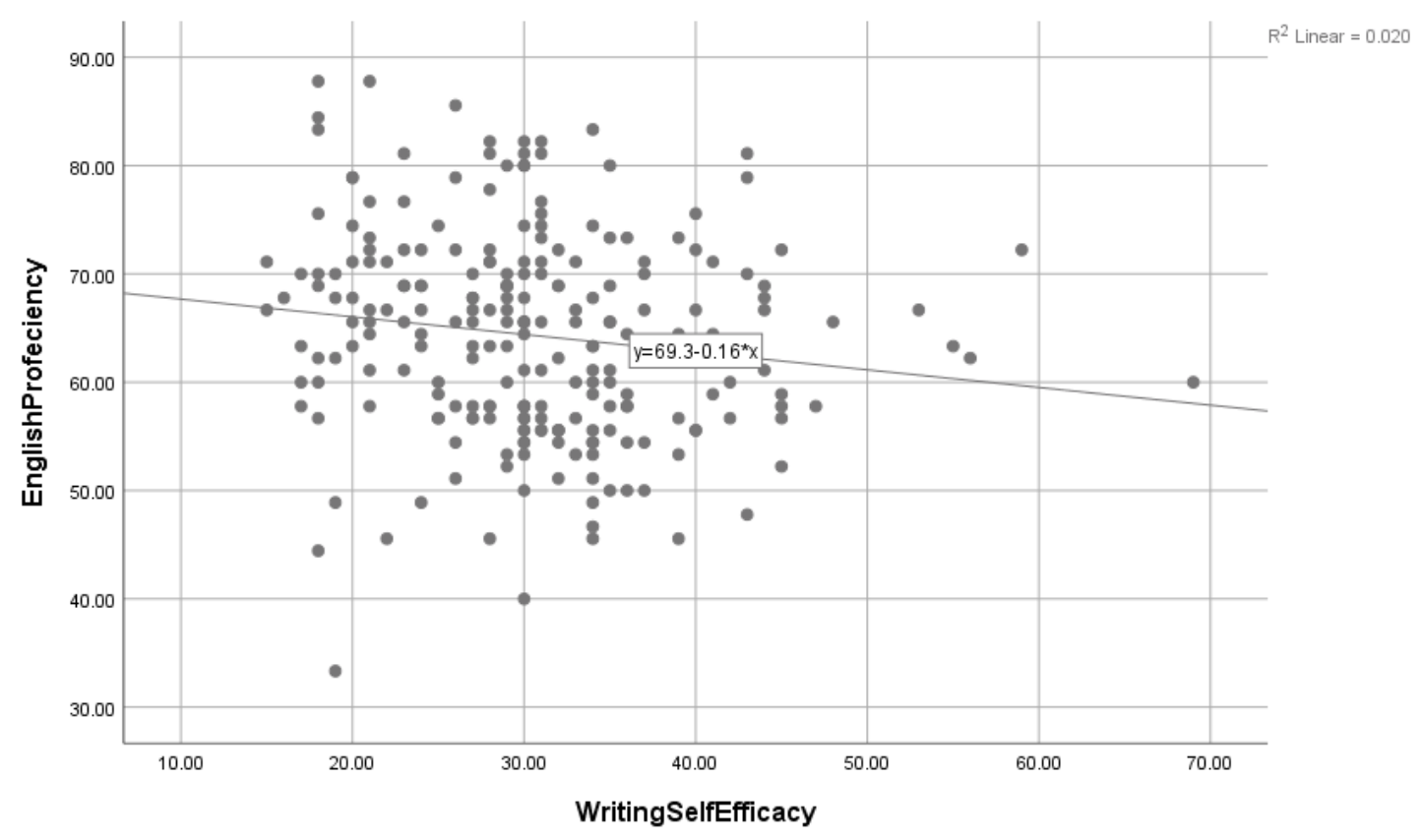

Figure 2. Linear Behavior Writing efficacy and English Proficiency

\section{Conclusion}

This research considerably concluded that teacher applicants have low positive Self- Efficacy towards English Proficiency tests. Also, respondents failed to demonstrate the expected proficiency level intended and expected from them. It proved that Reading Efficacy could not affect English Proficiency results. On the other hand, Writing Efficacy affects English Proficiency.

The level of self-efficacy in English readings of the teachers is approximately the same level across specialization. The teachers' English Writing Self -efficacy is different from each other with a moderate effect size. This research impacts DO 52, S. 1987 - The 1987 Policy on Bilingual Education that aims to achieve competence in both Filipino and English at the national level through the teaching of both languages and their use as media of instruction at all levels. Universities producing teachers may revive teacher candidates' self-efficacy towards the English language since it is the most used medium of instruction. Further, students' self-efficacy is significant to undergo evaluation before graduating to assess their overall readiness in using the English language to their future work that will affect job performance and satisfaction. Division of Romblon - Language Planning Department may 
use this study to assess self-efficacy towards English Proficiency Test of teacher applicants. This study can provide administrators with where shall they need to focus in terms of development.

\section{References}

Artino, A.R., (2012). Academic self-efficacy: from educational theory to instructional practice. Perspectives on Medical Education, 1, 76-85. https://doi.org/10.1007/s40037-012-0012-5

Beauvais, A.M., Stewart, J.G., De Nisco, S., Beauvais, J.E., (2014). Factors related to academic success among nursing students: a descriptive correlational research study. Nurse Education Today, 34(6), 918-23. https://doi.org/10.1016/j.nedt.2013.12.005

DePiper, J.N., Louie J., Nikula, J., Buffington, P., Tierney-Fife, P., Driscoll, M., (2021). Promoting teacher self-efficacy for supporting English learners in mathematics: effects of the Visual Access to Mathematics professional development. ZDM - Mathematics Education, 53, 489-502. https://doi.org/10.1007/s11858$\underline{021-01227-4}$

Digap, A.D., (2016). Self-Efficacy, English Proficiency and Effectiveness of Teachers of English in the Secondary Schools. SMCC Higher Education Research Journal, 2, 72-89. http://dx.doi.org/10.18868/sher2j.02.00416.07

Egel, I.P., (2009). The prospective English language teacher's reflections of self-efficacy, Procedia - Social and Behavioral Sciences, 1(1) 1561-1567. https://doi.org/10.1016/j.sbspro.2009.01.274

Feng, L., Hodges, T., Waxman, H., Malatesha, J.sR., (2019). Discovering the impact of reading coursework and discipline-specific mentorship on first-year teachers' self-efficacy: A latent class analysis. Annals of Dyslexia, 69(1), 80-98. https://doi.org/10.1007/s11881-018-00167-1

Jugo, R.R., (2020). Language Anxiety in Focus: The Case of Filipino Undergraduate Teacher Education Learners. Hindawi Education Research International, 2020, 1-8. https://doi.org/10.1155/2020/7049837

Khanshan, S.K., Yousef M.H. (2020). The relationship between self-efficacy and instructional practice of in-service soft disciplines, hard disciplines and EFL teachers, Asian-Pacific Journal of Second and Foreign Language Education, 5(1), 1-20. https://doi.org/10.1186/s40862-020-0080-8

McDonough, J., (2019). Classroom Management Self-Efficacy and New Teacher Retention. Digital Commons @ ACU, Electronic Theses and Dissertations, 163.

Meniado, J.C., (2018). Evaluating the English proficiency of faculty members of a higher education institution: Using results to develop responsive, professional development program. International Journal of English Linguistics, 9(2), 52-64. https://doi.org/10.5539/ijel.v9n2p52

Racca, M.A.B., Lasaten, R.C.S., (2016). English Language Proficiency and Academic Performance of Philippine Science High School Students, International Journal of Languages, Literature and Linguistics, 2(2), 44-49. http://dx.doi.org/10.18178/IJLLL.2016.2.2.65

Tanyera, S., (2015). The role of writing and reading self-efficacy in first-year preservice EFL teachers' writing performance. Procedia - Social and Behavioral Sciences, 199(3), 38-43 https://doi.org/10.1016/j.sbspro.2015.07.484

Topkaya, E., Yavuz, A., (2011). Democratic Values and Teacher Self-Efficacy Perceptions: A Case of Pre-Service English Language Teachers in Turkey, Australian Journal of Teacher Education, 36(8), 30-48. http://dx.doi.org/10.14221/ajte.2011v36n8.1

Wyatt, M., (2020). Research into Second Language Learners' and Teachers' Self-Efficacy Beliefs: Making the Connections. TESOL Quarterly: A Journal for Teachers of English to Speakers of Other Languages and of Standard English as a Second Dialect, 55(1), 296-307. https://doi.org/10.1002/tesq.3010 
Yilmaz, C., (2011). Teachers' perceptions of self-efficacy, English proficiency, and instructional strategies. Social Behavior and Personality an International Journal, 39(1), 91-100. https://doi.org/10.2224/sbp.2011.39.1.91

Authors Contribution: Both the authors equally contributed to this work.

Funding: No funding was received for conducting this study.

Conflict of Interest: The authors have no conflicts of interest to declare that they are relevant to the content of this article.

Does this article screened for similarity: Yes

Ethics Approval: This study was approved by Institution Ethics Committee

\section{About The License}

(C) The author(s) 2021. The text of this article is open access and licensed under a Creative Commons Attribution 4.0 International License

\section{Cite this Article}

Vanesa B. Dungog \& Joefel T. Libo-on, Teacher Applicants' Self-Efficacy and English Proficiency, Asian Journal of Interdisciplinary Research, 4(3) (2021) 30-36. https://doi.org/10.34256/ajir2133 